\title{
Determinants that Influencing the Adoption of E-HRM: An Empirical Study on Bangladesh
}

\author{
Abdul Kadar Muhammad Masum ${ }^{1,2}$, Mohammad Jonaed Kabir ${ }^{1}$ \& Mustafa Manir Chowdhury ${ }^{1}$ \\ ${ }^{1}$ Department of Business Administration, International Islamic University Chittagong, Chittagong, Bangladesh \\ ${ }^{2}$ Department of Administrative Studies \& Politics, University of Malaya, Kuala Lumpur, Malaysia \\ Correspondence: Abdul Kadar Muhammad Masum, Department of Administrative Studies \& Politics, University \\ of Malaya, Kuala Lumpur, Malaysia. Tel: 60-17-60-5543. E-mail: akmmasum@yahoo.com
}

Received: April 3, 2015 Accepted: April 15, 2015 Online Published: July 6, 2015

doi:10.5539/ass.v11n21p117 URL: http://dx.doi.org/10.5539/ass.v11n21p117

\begin{abstract}
Nowadays, information systems (ISs) have tremendous impact on processes and practices of human resource management (HRM). Realizing the effectiveness and efficiency of ISs, now, human resource (HR) managers are reliant on electronic human resource management (E-HRM) - an information system to accomplish HR activities. This system is implemented to reduce the administrative burden for HR professional thus they can deliver better services to firm's stakeholders (e.g., employees, managers). If the E-HRM is not adopted properly, management of human resource in an organization cannot work smoothly. This paper aims at exploring the determinants that influence the adaptation decision for E-HRM among firms in Bangladesh. This study developed research framework based on the theoretical foundation and previous literature in order to better investigate the relationship between individual, organizational, technological, and environmental determinants, and E-HRM adoption. A total number of 331 respondents were considered from forty six large scale private sector organizations in Bangladesh using stratified random sampling. Employees of the organizations responded a close-ended questionnaire based on a 5-point Likert scale. Here, data was analyzed by statistical tools, for example, descriptive statistics, and factor analysis. They study found top level management support, employee's individual attributes, system complexity, IT infrastructure, and industry pressure as the most influential determinants that influencing the adoption decision for E-HRM. Limitations and policy implications are discussed at the end of this paper. The scope of future studies is also addressed.
\end{abstract}

Keywords: electronic human resource management (E-HRM), influencing determinants, adaptation, firms, Bangladesh

\section{Introduction}

In the present knowledge economy, the performance of HRM undoubtedly related to organizational success (Masum, Azad, \& Beh, 2015). Recently, traditional HRM has been lifted its attention on strategic management of organizations through a significant contribution in strategic workforce analysis and knowledge sharing to achieve organizational goal (Lawler \& Mohrman, 2003). This shift is moderately attributed to human resource (HR) technologies such as E-HRM, HRIS - human resource information systems, and etc. Some researchers claimed that E-HRM has been interchangeably coined with Intranet-based HRM, virtual HRM, web-based HRM, and HRIS. Typically, E-HRM is defined as an integrated information system that comprises some applications of HR supply and demand forecast, HR planning, staffing information, recruitment and selection, information on training and development, pay increase, compensation forecast, promotion-related information, employee relations, and so on (Masum, Bhuiyan, \& Kabir, 2013). Due to its ease of speedy accessibility to information related to employees, E-HRM can improve the strategy of decision making process, and therefore it is considered as a strategic partner of the firms (Rodríguez \& Ventura, 2003).

There are some determinants that influence HR managers for implementing E-HRM. Previous studies show that research work that focuses the influential determinants to adopt e-HRM is limited, especially in developing economy as like Bangladesh. So, in Bangladesh, the implementation and usage of E-HRM can be considered as an innovation stage. Jahan (2014) reported that E-HRM was initiated at large organizations of Bangladesh in last 5 years. But, still now, its operation is partial and limited within the large organizations. Realization of the 
benefits from E-HRM by Public organizations and small organizations are failed and initiatives to implement E-HRM are inadequate in Bangladesh.

The foremost obstacle for implementing E-HRM is the shortage of management attention and fear of high cost, lack of experience, and lack of training on E-HRM (Jahan, 2014; Masum et al., 2013). But the advantages of the E-HRM are more than the limitations. Jahan (2014) stated that if E-HRM is implemented in the firms of Bangladesh, managers and employees will accept the systems. Though, E-HRM implementation is really a challenging task in Bangladesh.

The main thrust of this study is identifying most influential determinants that are related to managerial decision for adapting E-HRM in the private sector of Bangladesh. This study contributes to the knowledge of human resource management by exploring some important determinants that are under organizational, environmental, and technological issues, especially for developing countries. In search of our objective, the variables used in our analysis are selected by extensive literature review. Next, a conceptual framework of influencing determinants for E-HRM adoption is developed. In the next section, the methodology, and the results of the study are deliberated. Convinced final remarks and recommendations for future research are mentioned in the concluding section.

\section{Related Works}

Researchers identified some important determinants for adopting new technology. In this study, we examined some determinants for adopting E-HRM that taken from technology innovation literature. The influencing determinants are divided into individual level, organizational level, technological level, and environmental level. Authors of this paper have found that both qualitative and quantitative methods are available in innovation adoption research, though qualitative approach was widely visible.

Previous research proved that the effectiveness and success of HRIS largely remained in the hands of its end-users. Research on the technology acceptance model developed by Richter, Stocker, Müller, \& Avram (2013) has extensively examined the users' perception, attitude, motivation, intentions and adoption of information systems and technologies. This body of knowledge explains that users' attributes and their interaction with information system decide the success or failure of information systems and technologies implementation (Delorme \& Arcand, 2010; Troshani, Jerram, \& Rao Hill, 2011). In addition, Thong (1999) pointed out that CEO's attitude toward technology information has a great impact on the decision to IT adoption in Singapore small and medium sized enterprises (SMEs). Some researchers agreed that the IT expertise of the employees and their acquaintance with the electronic tools facilitate e-HRM adoption (Ruël, Bondarouk, \& Looise, 2004; Voermans \& van Veldhoven, 2007).

Organizational determinants represent some administrative characteristics which influence adoption of E-HRM. Strohmeier (2009) and Troshani et al. (2011) identified firm size, and supporting organization settings including a skilled workforce as significant determinants in effective innovation adoption. Moreover, top management support is essential to adopt a system in the organizations (Teo, Lim, and Fedric, 2007). They also identified skilled employee greatly influence the management commitment. Similarly, numerous researchers found that management commitment and their positive attitude on IT adoption plays a vital role to implement E-HRM in organizations (Altarawneh \& Al-Shqairat, 2010; Teo et al., 2007; Troshani et al., 2011). Additionally, Teo et al. (2007) stated that the availability of skilled professionals, who are also acquainted to IT, is precondition for effective and efficacious adoption of E-HRM. They denoted that it can be a foremost hindrance in E-HRM adoption if the end-users don't sufficient understanding of the system functions and features. Sizeable research found that the vital determinant in the effective implementation of E-HRM is the adequate financial support from the firms (Ngai \& Wat, 2006; Parsa, 2007; Reddick, 2009; Masum, 2015).

Technological determinants represent the manner where technology characteristics can influence adoption (Hoon Yang, Lee, \& Lee, 2007). Adopters assess the characteristics of innovations in terms of "possible gains and barriers". Gains refer to the benefits that organizations expect to receive upon adoption and include increased levels of service quality, efficiency, and reliability (Oliveira \& Martins, 2010). According to Rogers (2003), barriers include innovation compatibility and its complexity with organizational technology capability and legacy. Again, Rogers (2003) defined complexity as the degree to which an innovation is perceived as relatively difficult to understand and use. Moreover, a study on Singapore conducted by Teo et al. (2007) explored compatibility and relative advantage as significant determinants in managerial decision to implement E-HRM. Some researchers identified technological readiness as a major determinant for the decision of IT adoption in a firm. Oliveira and Martins (2010) stated that adequate IT professionals and strong organization's technology Infrastructure indicate the technology readiness of a firm. 
Environmental determinants describe the area where organizations conduct their business, and include industry characteristics, government regulation, and supporting infrastructure (Oliveira \& Martins, 2010; Troshani et al., 2011). Kittipong (2009) demonstrated that industry pressure is environmental determinant and it related with organizational adoption of innovation. In this study, industry pressure refers to the entire trend, direction of operational practices and extent of competition that drive a firm to adopt technology innovation so that it can achieve competitive advantages and can survive in the industry. According to Teo et al. (2007) and Masum (2015), competitive pressure or industry pressure compels a firm to adopt more strategic approach such as decreasing cost, and effectively and efficiently human resource management. Thong (1999) stated that a firm cannot be competitive without effective human resource management. Consequently, this pressure has driven the firms to implement and use E-HRM. Therefore, competition is counted as an influencing environmental determinant in adopting E-HRM.

\section{Research Model}

Researchers identified some influential determinants of E-HRM adoption. Among them, we examined some independent variables for E-HRM adoption among firms in Bangladesh. On the basis of past literature, a conceptual model was developed. The model indicates the determinants that influencing decision to adopt E-HRM in firm. This model consists of seven variables. These are employee's individual attribute (Delorme \& Arcand, 2010; Troshani et al., 2011; Richter et al., 2013), IT infrastructure (Kwon \& Zmud, 1987; Hoon Yang et al., 2007; Oliveira \& Martins, 2010; Masum, 2015), complexity (Thong, 1999; Rogers, 2003), compatibility (Rogers, 2003; Teo et al., 2007), top level management support (Teo et al., 2007; Altarawneh \& Al-Shqairat, 2010; Troshani et al., 2011; Masum, 2015); Industry pressure (Thong, 1999; Teo et al., 2007; Kittipong, 2009; Masum, 2015), and IT expertise (van Veldhoven \& Ruël et al., 2004; Voermans, 2007; Masum, 2015).

Independent variables

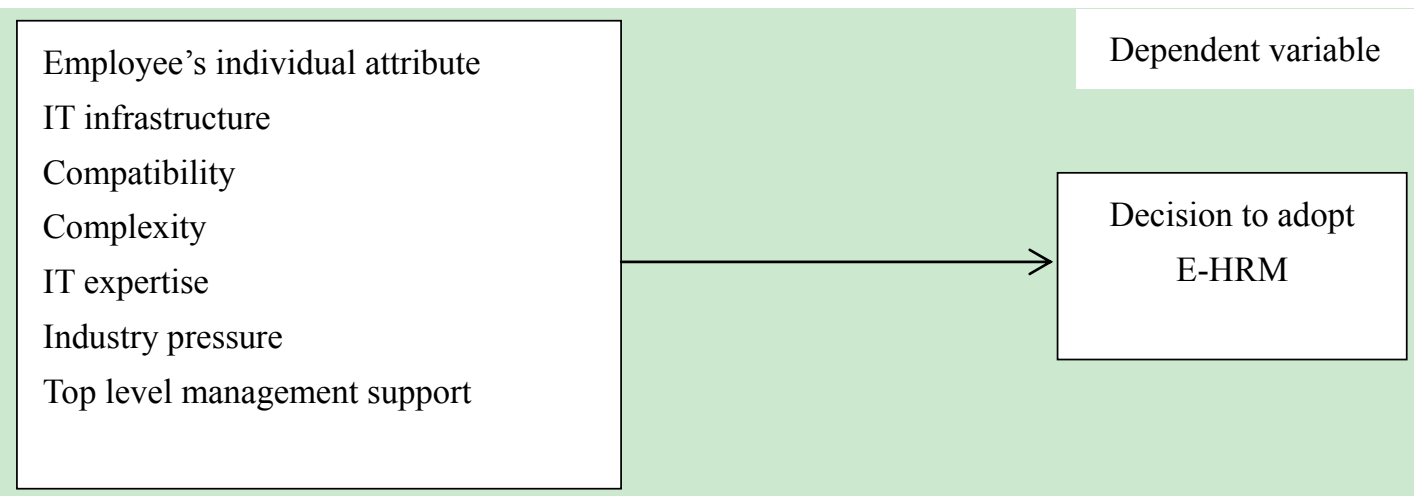

Figure 1. Research framework

\section{Methodology of the Study}

Quantitative techniques were adopted to explore the determinants that influencing E-HRM adoption. Three hundred and fifty questionnaires were sent to HR officer, Senior HR office, HR manager, HR executives, and IT experts of sample firms in Bangladesh. The useable questionnaires were 282 with the response rate $70.5 \%$. The close-ended questionnaire was distributed among the participants applying non-probability sampling technique. To measure selected independent variables, it was designed with a 5-point likert scale (where1 = strongly disagree, and $5=$ strongly agree). The survey was conducted for 2 months (October 2014 - November 2014). Descriptive statistics and exploratory factor Analysis (EFA) were used as statistical tools to analyze the collected data. Statistical Package for Social Sciences Program (SPSS) version 20.0 was used as statistical software.

\section{Data Analysis and Findings}

\subsection{Sample Characteristics}

Tables below demonstrated the results of the statistical analysis of sample characteristics, which includes organizations' size, and industry.

In Table 1, refer to organization size, the number of companies with less than 100 employee accounts for $6.5 \%$. The quantity of companies with less than 400 , but more than 200 is 10 , accounting for $21.8 \%$ of the total firms. There are 12 firms ( $26 \%$ ) that have people more than 500, but less than 1000 . Here, each bank represents only a branch. 
Table 1. Organizations' size statistics

\begin{tabular}{cccc}
\hline Number of employee & Frequency & Percent & Cumulative Percent \\
\hline$<100$ & 3 & 6.5 & 6.5 \\
$100-199$ & 6 & 13.1 & 19.6 \\
$200-399$ & 10 & 21.8 & 41.4 \\
$400-599$ & 5 & 10.9 & 52.3 \\
$600-799$ & 7 & 15.2 & 67.5 \\
$800-999$ & 12 & 26.0 & 93.5 \\
$>1000$ & 3 & 6.5 & 100.0 \\
Total & 46 & & \\
\hline
\end{tabular}

Table 2. Industry statistics

\begin{tabular}{cccc}
\hline Firm type & Frequency & Percent $\%$ & Cumulative Percent \\
\hline Banking & 12 & 26.0 & 26.0 \\
Education & 11 & 23.9 & 49.9 \\
Manufacturing & 13 & 28.3 & 78.2 \\
Telecommunication & 3 & 6.6 & 84.8 \\
Logistics/transportation & 7 & 15.2 & 100.0 \\
Total & 46 & & \\
\hline
\end{tabular}

Table 2 shows the industry statistics data of total forty six firms. There are $26 \%$ of the firms come from banking industry, the number of firms from the industry of education accounts for $23.9 \%$. $28.3 \%$ of the firms are manufacturing firms. $6.6 \%$ and $15.2 \%$ of the total firms are from telecommunication and logistics/transportation industry respectively.

\subsection{Validity and Reliability Analysis}

It is revealed that discriminant validity is satisfactory as these items more strongly loaded on single determinants than other determinants. It seems that there is much similarity on the content among HR manager's attitude, and IT expertise. Therefore, we combined the two construct into one single determinant, renamed employee's individual attribute. Here, most of the multi-item indicators confirmed enough convergent validity expect IT expertise and HR manager's attitude in factor analysis. For factor analysis, the sample size (331) was statistically significant. The sample was adequate as Kaiser-Meyer-Olkin (KMO) value for the overall matrix was 0.814 . To know the appropriateness of the data for factor analysis, we applied Bartlett's test of sphericity (Bartlett, 1950). The test value also was significant. We found very high reliability for our data by determining Cronbach's coefficient $(\alpha)$ value for each dimension. It was ranged from 0.76 to 0.92 (typically 0.6 and above is accepTable) (Cronbach, 1951; Malhotra, 2010).

\subsection{Determinants Extraction}

To identify the most influential determinants that influencing decision for E-HRM adoption, we employed Principal Component Analysis (PCA) followed by the varimax rotation. Table 1 includes 28 items, their loading value, Cronbach's alpha, and Eigen values. In this study, we considered the loading value of the variable as 0.50 and above. According to Hair, Anderson, Tatham, \& Black (2003) loading value 0.50 is significant for factor extraction. Due to lower loading value, we dropped some variable from our analysis (i.e., Com1, Com2, Comp1, Env3, and etc.). Now, the E-HRM adoption scales were reduced to 20 items. The factor analysis explored five determinants and together it explained $64.827 \%$ of the total variance.

Employee's individual attribute is the explored first determinant. This determinant is denoted by 6 variables (Att1, Att3, Att4, Exp4, Exp2, and Exp3). This explored factor explains $19.262 \%$ of the variance. The determinant loadings of the variables range from 0.598 to 0.811 . These 6 items are: I consider adoption of E-HRM as a wise decision for the company, I consider that E-HRM contributes to HRM strategic effectiveness, I consider that E-HRM contributes to HRM technical effectiveness, HR personnel knows how IT can be used to support HR activities, and employees' understanding of computer is better in comparison to other organizations in the industry, Employees fell comfort with E-HRM applications. 
Table 3. Summary of Rotated Component Matrix, Cronbach's alpha, variance and Eigen values

\begin{tabular}{|c|c|c|c|c|c|}
\hline Determinant Name & Items & Item loading & $\begin{array}{l}\% \text { of variance } \\
\text { (Cumulative) }\end{array}$ & $\begin{array}{l}\text { Cronbach's } \\
\text { Reliability } \\
\text { Coefficient }\end{array}$ & Eigen value \\
\hline \multirow{6}{*}{$\begin{array}{l}\text { Employee's individual } \\
\text { attribute }\end{array}$} & Att1 & 0.811 & \multirow{6}{*}{$\begin{array}{c}19.262 \\
(19.262)\end{array}$} & \multirow{6}{*}{0.85} & \multirow{6}{*}{9.986} \\
\hline & Att3 & 0.792 & & & \\
\hline & Att4 & 0.788 & & & \\
\hline & Exp4 & 0.785 & & & \\
\hline & Exp2 & 0.662 & & & \\
\hline & Exp3 & 0.598 & & & \\
\hline \multirow{4}{*}{ Top management support } & Top4 & 0.845 & \multirow{4}{*}{$\begin{array}{c}13.453 \\
(32.715)\end{array}$} & \multirow{4}{*}{0.83} & \multirow{4}{*}{5.326} \\
\hline & Top3 & 0.783 & & & \\
\hline & Top1 & 0.778 & & & \\
\hline & Top2 & 0.668 & & & \\
\hline \multirow{4}{*}{ IT infrastructure } & Infr2 & 0.812 & \multirow{4}{*}{$\begin{array}{c}11.116 \\
(43.831)\end{array}$} & \multirow{4}{*}{0.76} & \multirow{4}{*}{3.153} \\
\hline & Infr3 & 0.786 & & & \\
\hline & Infr4 & 0.645 & & & \\
\hline & Infr1 & 0.511 & & & \\
\hline \multirow{3}{*}{ Compatibility } & Comp2 & 0.782 & \multirow{3}{*}{$\begin{array}{c}9.654 \\
(52.485)\end{array}$} & \multirow{3}{*}{0.92} & \multirow{3}{*}{1.907} \\
\hline & Comp3 & 0.654 & & & \\
\hline & Comp4 & 0.578 & & & \\
\hline \multirow{3}{*}{ Competitive pressure } & Env1 & 0.712 & \multirow{3}{*}{$\begin{array}{c}8.342 \\
(60.827)\end{array}$} & \multirow{3}{*}{0.89} & \multirow{3}{*}{1.139} \\
\hline & Env2 & 0.594 & & & \\
\hline & Env4 & 0.523 & & & \\
\hline
\end{tabular}

Top level management support is the explored second determinant. This determinant is denoted by 4 variables (Top1, Top2, Top3, and Top4). This explored factor explains $13.453 \%$ of the variance. The determinant loadings of the variables range from 0.668 to 0.845 . These 4 items are: top management knows the advantages of E-HRM and they are enthusiastic to implement the system, They provides satisfactory financial support for IT infrastructure, They encourages HR personnel to use E-HRM in all HR related activities, and They has allocated adequate resources for E-HRM implementation.

IT infrastructure is the explored third determinant. This determinant is denoted by 4 variables (Infr2, Infr3, Infr4, and Infr1). This explored factor explains $11.116 \%$ of the variance. The determinant loadings of the variables range from 0.511 to 0.812 . These 4 items are: The firm has a secure networking system, the existing IT infrastructure is suitable for E-HRM, the firm has sufficient back up plan in case of disaster, and the firm has swift internet facility.

Compatibility is the explored forth determinant. This determinant is denoted by 3 variables (Comp2, Comp3, and Comp4). This explored factor explains $9.654 \%$ of the variance. The determinant loadings of the variables range from 0.578 to 0.782 . These 3 items are: E-HRM applications are compatible with existing organizational plan, the existing IT infrastructure is compatible with E-HRM applications, and E-HRM applications are compatible with existing digital data resources.

Industry pressure is the explored fifth determinant. This determinant is denoted by 3 variables (Env1. Env2, and Env4). This explored factor explains $8.342 \%$ of the variance. The determinant loadings of the variables range from 0.523 to 0.712 . These 3 items are: we keenly keep track of innovative usage of technology by competitors, E-HRM application is strategic need to strive in the industry, and the overall operational practices in our industry pressure us to adopt E-HRM.

The item loading values of Complexity was below 0.5 . So, this construct was dropped by PCA.

\section{Discussions}

The findings of the present study indicate that employee's individual attribute, top level management support, compatibility, IT infrastructure, and industry pressure are some influential determinants for managerial decision to adopt E-RM among firms in Bangladesh. However, complexity is not explored as a determinant i.e. it is not influencing decision to adopt E-HRM. 
Employee's individual attribute is the first explored determinant that is integration of two constructs - IT expertise and HR manager's attitude. Some researchers exposed that IT expertise (Ruël et al., 2004; Voermans \& van Veldhoven, 2007; Masum, 2015) and HR manager's attitude (Kittipong, 2009; Delorme \& Arcand, 2010; Troshani et al., 2011; Richter et al., 2013) affect technological adoption of any technological innovation that is alike with our findings. The earlier research found that top management support is a key factor for technology innovation (Teo et al., 2007; Hoon Yang et al., 2007; Altarawneh \& Al-Shqairat, 2010; Troshani et al., 2011; Masum, 2015). The explored determinant - top level management support is one of the influencing determinants to adopt E-HRM in firm of Bangladesh that is similar to the past research. Another most important extracted determinant to take decision for E-HRM adoption is IT Infrastructure that also supports the past research (Kwon \& Zmud, 1987; Hoon Yang et al., 2007; Oliveira \& Martins, 2010; Masum, 2015). The fourth extracted factor is compatibility with existing resource and organizational plan. The findings of Rogers (2003) and Thong (1999) are consistent to your present finding of the study. They identified that the compatibility nature of technology is most essential characteristics to adopt any new system. Finally, Industry pressure has influence to adopt E-HRM among firms in Bangladesh. Finally, industry pressure is explored as an influence determinant to adopt E-HRM. This finding is similar to previous studies (Kittipong, 2009; Teo et al., 2007; Thong, 1999; Masum, 2015).

\section{Conclusion}

E-HRM provides competitive advantages for supporting human resource management processes. It ensures easier, faster, and cheaper HR activity accomplishment and helps in all types of operational, functional and strategic human resource management processes. It helps to take more effective and strategic decision to solve HR problems. All these benefits of E-HRM can be attained seamlessly only if the system is adopted or adapted in an organization accurately and more effectively. However, there are some hindrances and challenging issues to implement and to adopt E-HRM all over the world. The purpose of this study was to examine determinants that influencing E-HRM adoption in firms of Bangladesh. The present study has contributed to the knowledge arena of human resource management through providing important insights and greater understanding into the determinants that influencing the managerial decision to adopt E-HRM in the context of developing countries. The findings of the study suggested that employee's individual attributes, top management support, IT infrastructure, compatibility, and industry pressure are the extracted determinants to the adoption of E-HRM. However, the findings of this study also suggested that employee's system complexity does not have an impact on the organizational adoption of E-HRM. Moreover, future studies are required in detecting the degree of the impact of these determinants identified. Additionally, many organizations are working in a global network in this globalization era. So, culture of both the country and the organization play an important role as influencing determinant in adopting E-HRM. As a result, the researchers strongly recommend investigating the aspect of other determinants including culture in E-HRM adoption.

\section{Limitations and Future Research}

During the preparation of this study, we found some limitations of it. Firstly, all selected firms in the sample are from Dhaka, the capital city of Bangladesh. As Dhaka is one of the districts out of 64, the findings of the study don't reflect the correct state of all firms in Bangladesh as a whole. Secondly, only 331 is the sample size of the present study. It is established that the larger the sample is more representative and produce better results. Thirdly, although there are a good number of potential determinants that influence the decision of E-HRM adoption, we have selected only 7 determinants to examine the decision of E-HRM adoption. The paper only concentrated on the decision to E-HRM adoption but not extent of E-HRM implementation. For further study, researchers can concentrate the implementation issues of E-HRM choosing a representative sample size.

\section{References}

Altarawneh, I., \& Al-Shqairat, Z. (2010). Human resource information systems in Jordanian universities. International Journal of Business and Management, 5(10), 113-123.

Bartlett, M. S. (1950). Tests of significance in determinant analysis. British Journal of statistical psychology, 3(2), 77-85. http://dx.doi.org/10.1111/j.2044-8317.1950.tb00285.x

Bondarouk, T., Ruel, H., \& van der Heijden, B. (2009). E-HRM effectiveness in a public sector organization: a multi-stakeholder perspective. The International Journal of Human Resource Management, 20(3), 578-590. http://dx.doi.org/10.1080/09585190802707359

Cronbach, L. J. (1951). Coefficient alpha and the internal structure of tests. psychometrika, 16(3), 297-334. http://dx.doi.org/10.1007/BF02310555

Delorme, M., \& Arcand, M. (2010). HRIS implementation and deployment: a conceptual framework of the new 
roles, responsibilities and competences for HR professionals. International journal of Business information systems, 5(2), 148-161. http://dx.doi.org/10.1504/IJBIS.2010.030626

Hair, J., Anderson, R., Tatham, R., \& Black, W. (2003). Multivariate data analysis. New Delhi: Peasrson Education.

Hoon Yang, K., Lee, S. M., \& Lee, S.-G. (2007). Adoption of information and communication technology: impact of technology types, organization resources and management style. Industrial Management \& Data Systems, 107(9), 1257-1275. http://dx.doi.org/10.1108/02635570710833956

Jahan, S. (2014). Human Resources Information System (HRIS): A Theoretical Perspective. Journal of Human Resource and Sustainability Studies, 2, 33-39. http://dx.doi.org/10.4236/jhrss.2014.22004

Kittipong, S. (2009). The adoption of techno-relationship innovations. Marketing Intelligent and Professionals, 27(3), 380-412.

Kwon, T. H., \& Zmud, R. W. (1987). Unifying the fragmented models of information systems implementation. Paper presented at the Critical issues in information systems research.

Lawler, E. E., \& Mohrman, S. A. (2003). HR as a strategic partner: What does it take to make it happen? Human Resource Planning, 26(3), 15-29.

Malhotra, N. (2010). Marketing Research: An applied orientation. New Jersey: Pearson Education.

Masum, A. K. M., Azad, M. A. K., \& Beh, L.-S. (2015). The role of human resource management practices in bank performance. Total Quality Management \& Business Excellence, 1-16. http://dx.doi.org/10.1080/ 14783363.2014.1002762

Masum, A. K. M. (2015). Adoption Factors of Electronic Human Resource Management (e-HRM) in Banking Industry of Bangladesh. Journal of Social Sciences, 10(5), 37-45

Masum, A. K. M., Bhuiyan, F., \& Kabir, R. (2013). HRIS Practices in Universities: An Exploratory Study on the Private Universities In Bangladesh. Global Journal of Human-Social Science Research, 13(7), 25-29.

Ngai, E., \& Wat, F. (2006). Human resource information systems: a review and empirical analysis. Personnel Review, 35(3), 297-314. http://dx.doi.org/10.1108/00483480610656702

Oliveira, T., \& Martins, M. F. (2010). Understanding e-business adoption across industries in European countries. Industrial Management \& Data Systems, 110(9), 1337-1354. http://dx.doi.org/10.1108/02635571011087 428

Parsa, H. (2007). Critical Determinants in Implementing HRIS in Restaurant Chains. Advances in Hospitality and Leisure, (3), 69-86.

Reddick, C. G. (2009). Human Resources Information Systems in Texas City Governments: Scope and Perception of its Effectiveness. Public Personnel Management, 38(4), 19-34. http://dx.doi.org/10.1177/ 009102600903800402

Richter, A., Stocker, A., Müller, S., \& Avram, G. (2013). Knowledge management goals revisited: A cross-sectional analysis of social software adoption in corporate environments. VINE, 43(2), 132-148. http://dx.doi.org/10.1108/03055721311329927

Rodríguez, J. M., \& Ventura, J. (2003). Human resource management systems and organizational performance: an analysis of the Spanish manufacturing industry. International Journal of Human Resource Management, 14(7), 1206-1226. http://dx.doi.org/10.1080/0958519032000114273

Rogers, E. M. t. e. (2003). Diffusion of Innovation (4th ed.). New York: The Free Press.

Ruël, H., Bondarouk, T., \& Looise, J. K. (2004). E-HRM: innovation or irritation. An explorative empirical study in five large companies on web-based HRM. Management Revue, 15(3), 364-380.

Strohmeier, S. (2009). Concepts of e-HRM consequences: a categorisation, review and suggestion. The International Journal of Human Resource Management, 20(3), 528-543. http://dx.doi.org/10.1080/095851 90802707292

Teo, T. S., Lim, G. S., \& Fedric, S. A. (2007). The adoption and diffusion of human resources information systems in Singapore. Asia Pacific Journal of Human Resources, 45(1), 44-62. http://dx.doi.org/10.1177/ 1038411107075402

Thong, J. Y. (1999). An integrated model of information systems adoption in small businesses. Journal of 
management information systems, 15(4), 187-214.

Troshani, I., Jerram, C., \& Rao Hill, S. (2011). Exploring the public sector adoption of HRIS. Industrial Management \& Data Systems, 111(3), 470-488. http://dx.doi.org/10.1108/02635571111118314

Voermans, M., \& van Veldhoven, M. (2007). Attitude towards E-HRM: an empirical study at Philips. Personnel Review, 36(6), 887-902. http://dx.doi.org/10.1108/00483480710822418

\section{Copyrights}

Copyright for this article is retained by the author(s), with first publication rights granted to the journal.

This is an open-access article distributed under the terms and conditions of the Creative Commons Attribution license (http://creativecommons.org/licenses/by/3.0/). 